\title{
What's trending at the Medical Journal of Australia? The current top 10 most-cited articles
}

\section{Authors and other experts reflect on the articles that made Journal history}

\footnotetext{
rom flares to hotpants to shoulder pads, we all know

how fashions change over time: but what about trends in citations? Ten years ago, as part of the 90th birthday celebrations of the Medical Journal of Australia, then Deputy Editor Ann Gregory examined the top 10 most-cited articles as of 2004. ${ }^{1}$ Now celebrating our 100 th birthday, the current editorial team have looked again at the most-cited articles, using the Web of Science (Thomson Reuters) citation analysis tool, which examines citations from 1949 to 2014 (Box). Since 2004, Cade ${ }^{2}$ has been supplanted in the number one position by the Quality in Australian Health Care Study, ${ }^{3}$ although Cade remains in the top 10 . The new entrants in many ways reflect current issues in health care: the rise in awareness of non-communicable diseases such as obesity and mental illness; the challenge of innovation in health care delivery; and the greater value placed on quality
}

evidence from clinical trials in medicine. Several authors of the top 10 articles and other experts in their respective fields have submitted short perspectives on their top 10 articles. We invite you to toast their success: a glass of Helicobacter pylori is optional.

\section{Diana R McKay MBBS(Hons), FRANZCP, MHM Deputy Editor \\ Medical Journal of Australia, Sydney, NSW. \\ mja@mja.com.au \\ doi: 10.5694/mjal4.00775}

1 Gregory AT. Jewels in the crown: The Medical Journal of Australia's 10 most-cited articles. Med J Aust 2004; 181: 9-12.

2 Cade JFJ. Lithium salts in the treatment of psychotic excitement. Med J Aust 1949; 2: 349-352.

3 Wilson RM, Runciman WB, Gibberd RW, et al. The Quality in Australian Health Care Study. Med J Aust 1995; 163: 458-471.

\section{Helicobacter pylori: what does it taste like?}

\section{The Journal's early support for a Helicobacter pioneer allowed publication of key results}

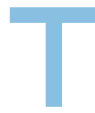

he title above is the most common question people ask me about the spiral bug. By the time this article comes to press the answer might even be published. But the question leads back to my paper in the MJA 29 years ago. ${ }^{1}$ It described the deliberate selfadministration of Helicobacter pylori and the observation that it caused an acute upper gastrointestinal illness with vomiting, halitosis and an underlying achlorhydria. Embarrassed to admit that it was a self-experiment, I wrote the paper in the third person at the suggestion of my coauthors, but they at least had witnessed my sufferings over a 14-day period, so it was not entirely subjective and anecdotal. It came to be published in the Journal because I had received a letter from the Editor at the time, Alistair Brass, saying how much he liked the Lancet paper I had coauthored with Robin Warren, ${ }^{2}$ and did I have any others up my sleeve on the subject? Warren and I had had such a bad run with editors by then that it seemed a breath of fresh air to meet an editor who actually liked original material. So I finished the paper and submitted it to the Journal in about September 1984. However, then showing his true colours, the Editor sent it out to scrupulous reviewers who asked for a complete rewrite, which made it a much better paper, but delayed its publication until April 1985. ${ }^{1}$

I obtained incredible value from the $M J A$ publication. Who knew that so many people were following the $M J A$ ? In a Lancet editorial soon afterwards, then Editor David Sharp "re-tweeted" the MJA paper, agreeing that $H$. pylori infection explained a mysterious illness that was spreading from time to time in gastroenterology laboratories performing acid secretion studies. ${ }^{3}$ An unnoticed infectious agent was contaminating their equipment and infecting many of the volunteers. ${ }^{4,5}$

Re-reading that paper every few years, I am impressed by how far the MJA Editor was "sticking his neck out" in allowing me to publish a hypothesis as to the cause of peptic ulcer. It was a further 5 years before journals allowed the word "cure" to appear in articles about duodenal ulcer, ${ }^{6}$ and almost a decade before mainstream United States journals could accept it as proven. ${ }^{7}$

\section{Barry J Marshall MBBS, FRACP, NL Clinical Professor of Microbiology}

Marshall Centre for Infectious Diseases Research and Training School of Pathology and Laboratory Medicine, University of Western Australia, Perth, WA.

bmarshall@hpylori.com.au doi: 10.5694/mjal4.00487

Competing interests: No relevant disclosures.

Provenance: Commissioned; not externally peer reviewed.

1 Marshall BJ, Armstrong JA, McGechie DB, Glancy RJ. Attempt to fulfil Koch's postulates for pyloric Campylobacter. Med J Aust 1985; 142: 436-439.

2 Marshall BJ, Warren JR. Unidentified curved bacilli in the stomach of patients with gastritis and peptic ulceration. Lancet 1984; 1: 1311-1315.

3 Pyloric Campylobacter finds a volunteer [editorial] Lancet 1985; 1: 1021-1022.

4 Ramsey EJ, Carey KV, Peterson WL, et al. Epidemic gastritis with hypochlorhydria. Gastroenterology 1979; 76: 1449-1457.

5 Gledhill T, Leicester RJ, Addis B, et al. Epidemic hypochlorhydria. Br Med J (Clin Res Ed) 1985; 290: 1383-1386.

6 Rauws EA, Tytgat GN. Cure of duodenal ulcer associated with eradication of Helicobacter pylori. Lancet 1990; 335: 1233-1235.

7 Marshall BJ. The 1995 Albert Lasker Medical Research Award. Helicobacter pylori. The etiologic agent for peptic ulcer. JAMA 1995; 274: 1064-1066. 


\section{After the Quality in} Australian Health Care Study, what happened?

\section{Milestones in Australia's journey to high-quality care}

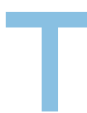

he 1995 Quality in Australian Health Care Study (QAHCS) demonstrated the potential to improve the quality and safety of health care. ${ }^{1-3}$ Using a modified version of the earlier Harvard Medical Practice Study on medical negligence, the QAHCS focused on the more useful measure of preventability of medical error. The incidence of adverse events was higher than in the Harvard study, and at first the Australian rates were queried by government: $16.6 \%$ of hospital admissions were associated with an adverse event, of which $51.2 \%$ were judged to have high preventability. Many countries replicated the Australian study, using one medical reviewer rather than two as in the QAHCS, which reduced the estimate by about $3 \%$. Overall, a consistent rate of about $10 \%$ of hospital admissions associated with an adverse event was seen in New Zealand, Japan, Singapore, the United Kingdom and Denmark. In 2012, a World Health Organization study on adverse events in developing countries showed a similar result. ${ }^{4}$

The Australian Government responded with a succession of initiatives: the Australian Council for Safety and Quality in Health Care was established by Australian health ministers in 2000 and operated until 2005; the Australian Commission on Safety and Quality in Health Care (ACSQHC) was created in 2006 and written into legislation with the National Health Reform Act 2011. The ACSQHC promulgated 10 national quality and safety standards as part of national accreditation processes. Health reform has also included the Independent Hospital Pricing Authority, the National Health Funding Body and the National Health Performance Authority. Linking costs to quality outcomes, combined with national comparative performance measures of safety, efficiency, access and patient experience, has to be considered a milestone in Australia's journey to highquality care.

Have the rates of adverse events declined? A repeat of the same study would be costly, and the changed context of health care would complicate interpretation. However, there have been significant process changes that reflect an increasing attention to quality. Federal and state governments are reporting infection rates and triage times. The Australian Council on Healthcare Standards reports annually on 360 indicators in Australasia and, for the years 2005-2012, more indicators improved (125) than worsened (38), with no significant trend for 62 indicators. ${ }^{5}$ For example, the proportions of emergency department presentations meeting the triage benchmarks increased by about $6 \%$ over the 8 -year period.

Quality principles have been introduced into medical and health professional education and expanded as a research theme. Early on, the University of Newcastle introduced a quality-of-care project, winning Australian Council on Healthcare Standards student quality improvement awards. ${ }^{6}$ Other schools have followed, and national and international curricula have been developed from Australia.

Notwithstanding the good progress, there remains much to do to improve health care systems. There is increasing focus on process re-engineering, applications of reliability science, human factor mitigation strategies, teamwork, communication, patient-based care and greater application of evidence-based medicine.

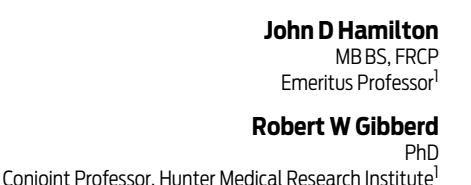

Conjoint Professor, Hunter Medical Research Institute ${ }^{l}$

Bernadette T Harrison MPH(Hons), GradCertMedEd, RN Clinical Lecturer ${ }^{2}$

1School of Medicine and Public Health, University of Newcastle, Newcastle, NSW.

2 Sydney Medical School, University of Sydney, Sydney, NSW.

jha06187@bigpond.net.au doi: 10.5694/mja14.00615

Acknowledgements: We acknowledge the MJA editors who allowed the study to take 14 pages and converted academic text into a readable format.

Competing interests: No relevant disclosures.

Provenance: Commissioned; not externally peer reviewed.

1 Wilson RM, Runciman WB, Gibberd RW, et al. The Quality in Australian Health Care Study. Med J Aust 1995; 163: 458-471.

2 Wilson RM, Harrison BT, Gibberd RW, Hamilton JD. An analysis of the causes of adverse events from the Quality in Australian Health Care Study. Med J Aust 1999; 170: 411-415.
3 Kable AK, Gibberd RW, Spigelman AD. Adverse events in surgical patients in Australia. Int J Qual Health Care 2002; 14: 269-276.

4 Wilson RM, Michel P, Olsen S, et al; WHO Patient Safety EMRO/AFRO Working Group. Patient safety in developing countries: retrospective estimation of scale and nature of harm to patients in hospital. BMJ 2012; 344: e832. doi: 10.1136/bmj.e832.

5 Australian Council on Healthcare Standards. Australasian clinical indicator report 2005-2012. Sydney: ACHS, 2013. http://www.achs.org.au/ publications-resources/australasian-clinicalindicator-report (accessed Jun 2014).

6 Australian Council on Healthcare Standards. Quality initiatives: entries in the 16th Annual ACHS Quality Improvement Awards 2013. Sydney: ACHS, 2013. http:// www.achs.org.au/media/78421/quality_initiatives_ entries_2013.pdf (accessed Jun 2014).

\section{Improving the mental health of the population: where to next?}

\section{The need for a national strategy on preventing mental disorders}

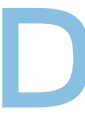

uring the 1990s, two national surveys were carried out in Australia that were very influential in guiding thinking about population mental health. The first was the National Survey of Mental Health and Wellbeing, which showed that mental disorders were common, disabling and undertreated. ${ }^{1}$ The second was the National Survey of Mental Health Literacy, which showed that many members of the public had negative views of the standard psychiatric treatments that were endorsed as effective by clinical practice guidelines and mental health clinicians. ${ }^{2,3}$

This "treatment gap" suggested a clear path to improving population mental health: we needed to get more people with mental disorders to seek help and receive evidence-based treatments. ${ }^{4}$ In Australia, efforts to achieve these aims were successful. There is now a greater willingness to be open about mental disorders and to seek help, ${ }^{5}$ and the Australian public's beliefs about treatment of mental disorders have become much closer to those of professionals. ${ }^{6}$ Further, we have seen considerable increases in use of pharmacological and psychological treatments. $^{7}$

However, the expected gains in population mental health have not been seen. Repeat population surveys since the 
1990s, using screening tests for mental disorders, show no detectable reduction in symptoms. ${ }^{7,8}$ The one population gain that has been found is a reduction in the suicide rate, which roughly coincided with the introduction of the National Suicide Prevention Strategy in 1999.9

These observations raise the question of "where to next?" One option would be to continue to expand the reach of clinical services and reduce the treatment gap further. However, it could be argued that the marginal gains of reducing the treatment gap will become progressively smaller as treatment is applied to milder cases.

An alternative strategy is to have a greater emphasis on prevention. ${ }^{10}$ The prevalence of mental disorders is a function of incidence and duration. Prevention aims to reduce incidence, whereas treatment aims to reduce duration. We need a twopronged effort aimed at both prevention and treatment, but the prevention prong is largely missing. It is notable that the reduction in suicide corresponded to the introduction of a strategy focused on population prevention. We need to build on this approach by developing a national strategy for the prevention of mental disorders.

$$
\begin{aligned}
& \text { Anthony F Jorm } \\
& \text { PhD, DSC }
\end{aligned}
$$

Acknowledgements: I am supported by National Health and Medical Research Council Australia Fellowship 566652.

\section{Competing interests: No relevant disclosures.}

Provenance: Commissioned; not externally peer reviewed.

1 Henderson S, Andrews G, Hall W. Australia's mental health: an overview of the general population survey. Aust N Z J Psychiatry 2000; 34: 197-205.

2 Jorm AF, Korten AE, Jacomb PA, et al. "Mental health literacy": a survey of the public's ability to recognise mental disorders and their beliefs about the effectiveness of treatment. Med J Aust 1997; 166: 182-186.

3 Jorm AF, Korten AE, Jacomb PA, et al. Helpfulness of interventions for mental disorders: beliefs of health professionals compared with the general public. Br J Psychiatry 1997; 171: 233-237.

4 Andrews G, Issakidis C, Carter G. Shortfall in mental health service utilisation. Br J Psychiatry 2001; 179: 417-425.

5 Reavley NJ, Jorm AF. Willingness to disclose a mental disorder and knowledge of disorders in others: changes in Australia over 16 years. Aust NZ J Psychiatry 2014; 48: 162-168.

6 Morgan AJ, Reavley NJ, Jorm AF. Beliefs about mental disorder treatment and prognosis: comparison of health professionals with the Australian public. Aust $N$ Z J Psychiatry 2014; 48: 442-451.

\section{The current top 10 most-cited articles*}

1. Wilson RM, Runciman WB, Gibberd RW, et al. The Quality in Australian Health Care Study. Med J Aust 1995; 163: 458-471.

2. Marshall BJ, Armstrong JA, McGechie DB, Glancy RJ. Attempt to fulfil Koch's postulates for pyloric Campylobacter. Med J Aust 1985; 142: 436439.

3. Marshall BJ, McGechie DB, Rogers PA, Glancy RJ. Pyloric Campylobacter infection and gastroduodenal disease. Med J Aust 1985; 142: 439-444.

4. Cade JFJ. Lithium salts in the treatment of psychotic excitement. Med J Aust 1949; 2: 349-352.

5. Jorm AF, Korten AE, Jacomb PA, et al. "Mental health literacy": a survey of the public's ability to recognise mental disorders and their beliefs about the effectiveness of treatment. Med J Aust 1997; 166: 182-186.

6. Cameron AJ, Welborn TA, Zimmet PZ, et al. Overweight and obesity in Australia: the 1999-2000 Australian Diabetes, Obesity and Lifestyle

7 Jorm A. The population impact of improvements in mental health services: the case of Australia. $\mathrm{Br} J$ Psychiatry 2011; 199: 443-444.

8 Jorm AF, Reavley NJ. Changes in psychological distress in Australian adults between 1995 and 2011. Aust N Z J Psychiatry 2012; 46: 352-356.

9 Page A, Taylor R, Martin G. Recent declines in Australian male suicide are real, not artefactual. Aust NZ J Psychiatry 2010; 44: 358-363.

10 Jacka FN, Reavley NJ, Jorm AF, et al. Prevention of common mental disorders: what can we learn from those who have gone before and where do we go next? Aust N Z J Psychiatry 2013; 47: 920-929.

\section{Cade"s lithium: an extraordinary experiment with a not-so-ordinary element}

\section{Lithium research continues to yield benefits for treatment of bipolar disorder}

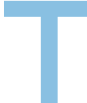

o those familiar with the properties of lithium, it was no surprise that John Cade's seminal article ${ }^{1}$ was, in 2004, the most cited in the history of the Journal, and was aptly described as a jewel in the crown. ${ }^{2}$ After all, lithium has long had royal status in clinical practice guidelines and is very much in its element in blue blood. ${ }^{3}$ Hence, the fact that another decade later Cade's groundbreaking study has retained regal standing in the archives of the Journal is to be expected. But perhaps what is truly remarkable is the fact that lithium has recently strengthened its clinical profile in the pharmacological armamentarium presently used to treat bipolar disorder. ${ }^{4}$ This resurgence of interest reflects lithium's enduring efficacy - put bluntly, it works. Lithium is arguably the best agent for the most critical phase of bipolar disorder, long-term prophylaxis, and as such it is the only true mood stabiliser. ${ }^{5}$ Boosting its profile further, lithium is both antisuicidal $^{6}$ and neuroprotective. ${ }^{4}$

Unfortunately, lithium can be toxic, acutely so at high doses, but also at low doses when administered chronically, although the true risks have been somewhat exaggerated. ${ }^{7}$ As the only antimanic agent, it would be useful to understand its mechanism of action, so as to target those patients most likely to respond and to develop mimetics that can replicate lithium's specific actions without reproducing its tolerability problems. Recent studies have identified genetic variations associated with lithium response, ${ }^{8}$ and potential lithium-like molecules are undergoing development. ${ }^{9}$ These ambitious endeavours aim to advance the treatment of bipolar disorder and, in doing so, will provide more robust means for defining the illness and equating diagnoses to disease. A lithiumresponsive and lithium-defined subtype of bipolar disorder representing a biologically anchored phenotype could be called Cade's 


\section{in the Medical Journal of Australlia}

Study (AusDiab). Med J Aust 2003; 178: 427-432.

7. Plint AC, Moher D, Morrison A, et al. Does the CONSORT checklist improve the quality of reports of randomised controlled trials? A systematic review. Med J Aust 2006; 185: 263-267.

8. Grol R, Wensing M. What drives change? Barriers to and incentives for achieving evidence-based practice. Med J Aust 2004; 180 (6 Suppl): S57-S60.

9. Bellomo R, Goldsmith D, Uchino S, et al. A prospective before-and-after trial of a medical emergency team. Med J Aust 2003; 179: 283-287.

10. Bower C, Stanley FJ. Dietary folate as a risk factor for neural tube defects: evidence from a case-control study in Western Australia. Med J Aust 1989; 150: 613-619.

*As at 12 May 2014. Source: Web of Science (Thomson Reuters).

disease..$^{10}$ Alas, although this would be a tremendous acknowledgement, perhaps the eponym would be better suited to describing the remedy that he discovered.

Gin S Malhi MD, FRCPsych, FRANZCP Professor

Discipline of Psychiatry, University of Sydney, Sydney, NSW. gin.malhi@sydney.edu.au doi: 10.5694/mjal4.00555

Competing interests: No relevant disclosures.

Provenance: Commissioned; not externally peer reviewed.

1 Cade JFJ. Lithium salts in the treatment of psychotic excitement. Med J Aust 1949; 2: 349-352.

2 Gregory AT. Jewels in the crown: The Medical Journal of Australia's 10 most-cited articles. Med J Aust 2004; 181: 9-12.

3 Malhi GS. The king is dead, long live the king! The restoration of BALANCE. Bipolar Disord 2010; 12: 681-684.

4 Malhi GS. [Lithium: an element of blue blood?] [French] Ann Med Psychol (Paris) 2014; 172: 155-157.

5 Goodwin GM, Malhi GS. What is a mood stabilizer? Psychol Med 2007; 37: 609-614.

6 Cipriani A, Hawton K, Stockton S, Geddes JR. Lithium in the prevention of suicide in mood disorders: updated systematic review and meta-analysis. $B M J$ 2013; 346: f3646.

7 Mcknight R, Adida M, Budge K, et al. Lithium toxicity profile: a systematic review and meta-analysis. Lancet 2012; 379: 721-728.

8 Chen CH, Lee CS, Lee MT, et al. Variant GADLl and response to lithium therapy in bipolar I disorder. $N$ Engl J Med 2014; 370: 119-128.

9 Singh N, Halliday AC, Thomas JM, et al. A safe lithium mimetic for bipolar disorder. Nat Commun 2013; 4: 1332.

10 Ghaemi SN, Ko JY, Goodwin FK. "Cade's disease" and beyond: misdiagnosis, antidepressant use, and a proposed definition for bipolar spectrum disorder. Can J Psychiatry 2002; 47: 125-134.

\section{What will it take to curb the rise in obesity?}

\section{Shifting a whole population towards a healthy weight requires action targeting the root causes of obesity}

T he headline finding from our 2003 paper was a 2.5-times increase in the prevalence of obesity since 1980, with $20.8 \%$ of Australian adults found to be obese. Reporting the national obesity prevalence for the first time since 1995, this paper was one of the key outcomes from the Australian Diabetes, Obesity and Lifestyle study (AusDiab). ${ }^{1}$ AusDiab was the first Australian national diabetes study; it showed an adult prevalence of diabetes of $7.4 \%$ and that of prediabetes (elevated blood glucose levels but below the cutpoint for diabetes) at $16.4 \% .{ }^{2}$ These figures meant that prevention of the twin epidemics of obesity and diabetes was placed very much on the national agenda. AusDiab went on to become a longitudinal study, with the follow-ups of the cohort at 5 and 12 years providing invaluable data for studying obesity, diabetes, prediabetes, hypertension and kidney disease in individuals as they age. The more than 200 papers now published using data from this study have played an important role in influencing national public health policy and action.

With the prevalence of obesity continuing to climb since the baseline AusDiab survey (28.3\% in the 2011-12 National Health Survey ${ }^{3}$ ), it is becoming clear that the lifestyle change programs and medical interventions that are often successful in trials and for individuals are effectively individual sandbags against the flood of obesity. Successfully shifting a whole population towards a healthy weight is likely to also require action targeting some of the root causes of obesity. Our increasingly sedentary and inactive lifestyles in combination with an environment full of cheap, tasty, heavily marketed and energydense foods make us highly susceptible to weight gain. Although we are each responsible for our own behaviour, these environmental and cultural factors combine to effectively conspire against healthy choices. ${ }^{4}$ In addition, a focus on adult lifestyles, although important, ignores the increasing body of data suggesting that the genesis of adult obesity is biological and cultural factors operating very early in life. ${ }^{5}$

A promising next generation of environmental obesity prevention initiatives include the excellent work done to improve the school food environment in many countries (now championed in the United States by First Lady Michelle Obama ${ }^{6}$ ), wholeof-community interventions such as the Healthy Together Communities program in Victoria ${ }^{7}$ and excellent work by researchers, ${ }^{8}$ retailers ${ }^{9}$ and others ${ }^{10}$ to change the way food is marketed and sold. Obesity prevention in mothers and in infants ${ }^{11}$ and prevention of excess gestational weight gain are further promising approaches. The combination of initiatives such as these will hopefully mean that when the Journal celebrates another decade, we will also be finally able to celebrate a reduction in Australia's obesity prevalence.

\footnotetext{
Adrian J Cameron GradDipIntlHealth, MPH, PhD Senior Research Fellow

Paul Z Zimmet MD, PhD, FRACP Director Emeritus ${ }^{2}$
} 
IWHO Collaborating Centre for Obesity Prevention Deakin University, Melbourne, VIC.

2 Baker IDI Heart and Diabetes Institute, Melbourne, VIC.

adrian.cameron@deakin.edu.au doi: 10.5694/mjal4.00553

Acknowledgements: Adrian Cameron is supported by a fellowship from the National Health and Medical Research Council (1013313).

\section{Competing interests: No relevant disclosures.}

Provenance: Commissioned; not externally peer reviewed.

1 Cameron AJ, Welborn TA, Zimmet PZ, et al. Overweight and obesity in Australia: the 1999-2000 Australian Diabetes, Obesity and Lifestyle Study (AusDiab). Med J Aust 2003; 178: 427-432.

2 Dunstan DW, Zimmet PZ, Welborn TA, et al. The rising prevalence of diabetes and impaired glucose tolerance: the Australian Diabetes, Obesity and Lifestyle Study. Diabetes Care 2002; 25: 829-834.

3 Australian Bureau of Statistics. Australian Health Survey: first results, 2011-12. Canberra: ABS, 2012. (ABS Cat. No. 4364.0.55.001.) http://www.ausstats.abs.gov.au/ausstats/ subscriber.nsf/0/1680ECA402368CCFCA2 57AC90015AA4E/\$File/4364.0.55.001.pdf (accessed May 2014).

4 Moodie R, Stuckler D, Monteiro C, et al. Profits and pandemics: prevention of harmful effects of tobacco, alcohol, and ultra-processed food and drink industries. Lancet 2013; 381: 670-679.

5 Gluckman PD, Hanson M, Zimmet P, Forrester T. Losing the war against obesity: the need for a developmental perspective. Sci Transl Med 2011; 3: $93 \mathrm{cml} 9$.

6 The White House. The White House and USDA announce School Wellness Standards [media release]. 25 Feb 2014 http://www.whitehouse.gov/the-pressoffice/2014/02/25/white-house-and-usdaannounce-school-wellness-standards (accessed Feb 2014).

7 Victorian Government Department of Health. Healthy Together Victoria. 2011 http://www.health.vic.gov.au/prevention/ healthytogether.htm\#healthy (accessed Apr 2014).

8 Foster GD, Karpyn A, Wojtanowski AC, et al. Placement and promotion strategies to increase sales of healthier products in supermarkets in low-income, ethnically diverse neighborhoods: a randomized controlled trial. Am J Clin Nutr 2014; 99 : 1359-1368.

9 The Food Trust, Robert Wood Johnson Foundation. Harnessing the power of supermarkets to help reverse childhood obesity. Princeton, NJ: RWJF, 2011. http:// www.rwjf.org/content/dam/farm/reports/ reports/2011/rwjf69943 (accessed May 2014).

10 Australian Food Sovereignty Alliance. People's food plan. http://www.australianf oodsovereigntyalliance.org/peoples-foodplan (accessed Apr 2014).

11 Campbell KJ, Lioret S, McNaughton SA, et al. A parent-focused intervention to reduce infant obesity risk behaviors: a randomized trial. Pediatrics 2013; 131: 652-660.
Child health - how is Australia doing and what more do we need to do for our kids?

\section{Focusing on the health and wellbeing of our children is the most important investment Australia can make}

ustralia is similar to other wealthy Western democracies for many aspects of child and youth health and wellbeing but, despite our material wealth, Australian rates of vaccination, obesity, child abuse and neglect do not compare well, and youth unemployment and the gap between rich and poor are increasing. ${ }^{1,2}$ Canadian researchers suggest that an unwanted outcome of economies focusing heavily on wealth creation is an impoverishment of the health and wellbeing of children, which will affect adult health and the human capability of nations so-called modernity's paradox. ${ }^{3}$

Problems including developmental delays, substance misuse, child maltreatment and obesity and overweight are occurring at such high rates that they are already putting pressure on our health and welfare services. Most of these problems do not have effective treatments, hence they demand an urgent preventive approach. With a third of Australian children now overweight or obese, baby boomers may be the last generation to live longer than their parents, given the disease complications that will result. ${ }^{4}$

Further, mental health problems including substance misuse and autism appear to be increasing, or at least increasingly diagnosed. ${ }^{5}$ The impact on children of increasing mental health problems and substance misuse in their parents is hard to quantify and likely to be enormous. ${ }^{6}$ In a healthy country like Australia, it is unacceptable that many child health problems are much more prevalent in Aboriginal populations.

Can we replicate the successes of population interventions such as folate supplementation for preventing neural tube defects ${ }^{7,8}$ and supine sleeping for preventing sudden infant death syndrome? ${ }^{9}$ Surely some measures, such as improved vaccination coverage and prevention of prenatal alcohol exposure, are achievable. Most interventions will require collaborative action on multiple fronts outside health and with increased attention to social, economic and health inequalities. No issue is more urgent than climate change, which will have a disproportionately greater effect on child health. ${ }^{10}$ Let's hope the dithering, delaying, denying and disparaging of the scientific evidence does not mean it is too late.

Australia really is a lucky country, but if we want future prosperity, then focusing on the health and wellbeing of our children is one of the most important investments we can make.

Fiona J Stanley MSc, MD

Patron, ' and Distinguished Research Professor ${ }^{2}$

Carol Bower

MBBS, MSC

Senior Principal Research Fellow, Population Health ${ }^{1}$

1 Telethon Kids Institute, Perth, WA.

2 School of Paediatrics and Child Health, University of Western Australia, Perth, WA.

fiona.stanley@telethonkids.org.au doi: 10.5694/mjal4.00545

Competing interests: No relevant disclosures.

Provenance: Commissioned; not externally peer reviewed.

1 Commission on the Social Determinants of Health Closing the gap in a generation: health equity through action on the social determinants of health. Geneva: World Health Organization, 2008. http://www.who.int/ social_determinants/thecommission/finalreport/en/ index.html (accessed May 2014)

2 Australian Research Alliance for Children and Youth. Report card: the wellbeing of young Australians. Canberra: ARACY, 2013. http://www.aracy.org.au/ documents/item/126 (accessed May 2014).

3 Keating DP, Hertzman C, editors. Developmental health and the wealth of nations: social, biological, and educational dynamics. New York: Guilford Press, 1999.

4 Gray V, Holman CD. Deaths and premature loss of life caused by overweight and obesity in Australia in 20112050: benefits from different intervention scenarios. Report for the Australian Preventative Health Taskforce. Perth: University of Western Australia, 2013.

5 Nassar N, Dixon G, Bourke J, et al. Autism spectrum disorders in young children: effect of changes in diagnostic practices. Int J Epidemiol 2009; 38: 1245-1254.

6 O'Donnell M, Anderson D, Morgan VA, et al. Trends in pre-existing mental health disorders among parents of infants born in Western Australia from 1990 to 2005. Med J Aust 2013; 198: 485-488.

7 Bower C, Stanley FJ. Dietary folate as a risk factor for neural-tube defects: evidence from a case-control study in Western Australia. Med J Aust 1989; 150: 613-619.

8 De-Regil LM, Fernández-Gaxiola AC, Dowswell T, PeñaRosas JP. Effects and safety of periconceptional folate supplementation for preventing birth defects. Cochrane Database Syst Rev 2010; (10): CD007950.

9 Dwyer T, Ponsonby AL. Sudden infant death syndrome and prone sleeping position. Ann Epidemiol 2009; 19: 245-249.

10 McMichael AJ. Climate change: health risks mount while Nero fiddles. Med J Aust 2014; 200: 507-508. 